\title{
Preparation and characterization of lapatinib-loaded PVP nanofiber amorphous solid dispersion by electrospinning
}

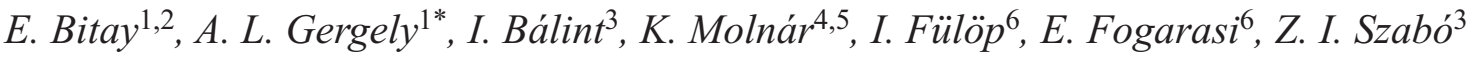 \\ ${ }^{1}$ Department of Mechanical Engineering, Faculty of Technical and Human Sciences, Sapientia Hungarian University of \\ Transylvania, Târgu-Mureş, Corunca, 1C, 540485 Târgu-Mureş, Romania \\ ${ }^{2}$ Research Institute of the Transylvanian Museum Society, 2-4 Napoca, 400009 Cluj, Romania \\ ${ }^{3}$ Department of Drugs Industry and Pharmaceutical Management, George Emil Palade University of Medicine, Pharmacy, \\ Science, and Technology of Târgu-Mureş, Gh. Marinescu 38, 540485 Târgu-Mureş, Romania \\ ${ }^{4}$ Department of Polymer Engineering, Faculty of Mechanical Engineering, Budapest University of Technology and \\ Economics, Múegyetem rkp. 3., H-1111 Budapest, Hungary \\ ${ }^{5}$ MTA-BME Research Group for Composite Science and Technology, Müegyetem rkp. 3, H-1111 Budapest, Hungary \\ ${ }^{6}$ Department of Toxicology and Biopharmacy, George Emil Palade University of Medicine, Pharmacy, Science, and \\ Technology of Târgu-Mureş, Gh. Marinescu 38, 540485 Târgu-Mureş, Romania
}

Received 3 May 2021; accepted in revised form 26 June 2021

\begin{abstract}
Lapatinib-loaded polyvinylpyrrolidone-based nanofibrous solid dispersions were prepared by electrospinning in order to enhance the aqueous solubility and dissolution rate of the anticancer drug. The prepared nanofibers were characterized by smooth-surfaced, homogenous filaments with average diameters of $462 \pm 160 \mathrm{~nm}$ determined by scanning electron microscopy. The crystalline to amorphous transition of the active ingredient was confirmed by differential scanning calorimetry, while Raman spectroscopy showed that amorphous lapatinib was uniformly distributed in the fibrous structures. Gas chromatographic analyses revealed that residual solvents in the nanofiber mats were below the ICH Guideline Q3C recommended limits, namely ethanol $10.9 \pm 2.3 \mathrm{ppm}$ (recommended limit $5000 \mathrm{ppm}$ ) and dimethyl formamide $780 \pm 56 \mathrm{ppm}$ (recommended limit $880 \mathrm{ppm}$ ). Determination of drug content and in vitro dissolution studies were performed in order to observe the influence of electrospinning on the drug release characteristics of the product obtained. The lapatinib content in the nanofibers were measured to be $16.76 \pm 0.11 \mathrm{w} / \mathrm{w} \%$, whereas the dissolution study at $\mathrm{pH} 6.8$ indicated a rapid disintegration of the nanofibrous mats, releasing $\sim 70 \%$ of the drug loading under 5 minutes compared to the $\sim 0.05 \%$ dissolution of the neat lapatinib ditosylate. The results confirm the applicability of electrospinning for the improvement of physicochemical characteristics of the poorly bioavailable anticancer agent.
\end{abstract}

Keywords: processing technologies, lapatinib ditosylate, dissolution, electrospinning, solid dispersion

\section{Introduction}

In most countries, cancer ranks as one of the leading causes of death before the age of 70 years. According to recently published estimates, 19.3 million new cancer cases and around 10 million cancer deaths occurred worldwide in 2020. Among the different types, female breast cancer was the most frequently diagnosed cancer ( $11.7 \%$ of all cancer cases), surpassing lung cancer $[1,2]$. Approximately $15-20 \%$ of breast cancer cases can be characterized by an overexpression of human epidermal growth factor receptor 2 (HER2) $[3,4]$, and these cases tend to be more aggressive than the other types of breast cancers, respond more poorly to chemotherapy [5] and have a higher recurrence rate [6] and metastasis potential $[4,7,8]$. The use of anti-HER2 agents has yielded

${ }^{*}$ Corresponding author, e-mail: agergely@ms.sapientia.ro (C) BME-PT 
good levels of efficacy and substantially improved outcomes of patients with HER2-positive breast cancers; however, increasing drug resistance remains a challenge $[4,7,8]$.

Lapatinib (LAP) is a potent and reversible dual inhibitor of both HER1 (also known as epidermal growth factor receptor, or shorty EGFR) and HER2 tyrosine kinases [9]. The marketed film-coated tablet formulation contains the ditosylate monohydrate salt (LAP-DT), and it is currently approved for the treatment of certain cases of advanced or metastatic breast cancer in combination with capecitabine or letrozole [10]. Although LAP displays a high selectivity towards the abovementioned tyrosine kinases, it is also plagued by being far from optimal pharmacokinetic properties. LAP is reported to be a Biopharmaceutics Classification System (BCS) Class IV drug [11], characterized by low bioavailability [12], associated with poor, $\mathrm{pH}$-dependent aqueous solubility and low permeability [13]. It also displays high interpatient variability, and both food intake and gastric $\mathrm{pH}$ affect its bioavailability $[12,14,15]$. Due to these drawbacks, large daily doses (1250-1500 mg) are needed, taken once daily, in the form of 56 tablets, which can decrease patient compliance and increase the side effects of the anticancer drug. Improving the oral bioavailability of the tyrosine kinase inhibitor through a novel formulation with enhanced solubility and dissolution rate could potentially reduce daily doses, improve treatment outcomes, and possibly reduce the side effects.

There are several well-known solubility enhancement techniques, such as salt- or prodrug formation, particle size reduction, complexation, emulsion formation, and preparation of solid dispersions, just to name a few [16-19]. Some of these techniques were also applied in order to enhance the solubility of LAP.

Song et al. [20] used spray drying to prepare solid dispersion of LAP and four frequently used polymers in the pharmaceutical industry, namely Soluplus ${ }^{\circledR}$, polyvinylpyrrolidone vinyl acetate (PVPVA), hydroxypropyl methylcellulose acetate succinate (HPMCAS), and hydroxypropyl methylcellulose phthalate (HPMCP). The authors' findings indicate a large increase in the dissolution of LAP from the solid dispersions compared to that of neat LAP $(\sim 5 \%)$. The dissolution experiments were conducted in $500 \mathrm{ml}$ of $0.2 \%(\mathrm{w} / \mathrm{v})$ sodium dodecyl sulfate (SDS) medium in water at $37^{\circ} \mathrm{C}$. SDS was used to increase the apparent solubility of LAP. The best dissolution results
( $~ 80 \%$ LAP dissolved after $120 \mathrm{~min}$ ) was obtained with solid dispersions prepared with HPMCAS at $40 \%$ drug loading. Hu et al. [21] used solvent rotary evaporation (SRE) and hot-melt extrusion (HME) to prepare solid dispersion of LAP, Soluplus ${ }^{\circledR}$, and Poloxamer 188 with a particle size of $\sim 150 \mu \mathrm{m}$. The dissolution media was $900 \mathrm{ml}$ of $0.1 \mathrm{~N} \mathrm{HCl}$ with $2 \%$ polysorbate 80 at $37^{\circ} \mathrm{C}$. To compensate for the gelation tendency of Soluplus ${ }^{\circledR}$, thus inhibiting the dissolution of LAP, $5 \mathrm{w} / \mathrm{w} \%$ potassium bicarbonate was added to all samples. Under these conditions, $\sim 60 \%$ of the free LAP dissolved after 60 minutes, whereas the solid dispersion prepared by SRE released $\sim 92 \%$ of the drug under the same time period. The authors concluded that SRE was a better way to produce solid dispersions for the studied system than HME, since in the former, all LAP was in the amorphous state, whereas in the latter some of the LAP was still in the crystalline state. Mitrabhanu et al. [22] prepared solid dispersions of LAP and Eudragit ${ }^{\circledR}$ EPO (cationic), Eu$\operatorname{dragit}^{\circledR}$ L 100-55 (anionic), HPMCP HP-55 (anionic), HPMC-AS (anionic), and Povidone (polyvinyl pyrrolidone) K30 (non-ionic) polymers at different ratios. Solvent-controlled coprecipitation, fusion, nanoprecipitation, and spray drying techniques were employed to prepare supersaturated solid dispersions. The authors claim that solid dispersion significantly improves the dissolution of LAP in the studied dissolution media, indifferent from the $\mathrm{pH}$. Further studies showed that amorphization of LAP by preparing coreshell nanoparticles [23] or incorporating LAP and doxorubicin into block copolymer micelles could increase the dissolution and bioavailability [24].

The abovementioned research suggests that solid dispersion preparation and amorphization of LAP increases the solubility and the dissolution of the drug. To the authors' knowledge, electrospinning was not employed to prepared solid dispersion of LAP. In recent years electrospinning has become a convenient and easily accessible method to prepare solid dispersion of different drug-polymer systems, as is summarized recently by Yu et al. [25] in review. The produced fibers are in the sub-micron or couple of micrometer range, thus increasing the surface-to-volume ratio of the produced fiber mats, which could also influence the disintegration rate of the solid dispersion, thus the dissolution of the encapsulated active pharmaceutical ingredient (API) $[26,27]$. The working principle of electrospinning has been discussed extensively in the literature. Briefly, the electrospinning 
process involves the preparation of a polymeric solution with suitable viscosity and conductivity which is pumped through a capillary or needle with the help of a syringe pump. A high voltage DC source is used to create an electric field between the capillary and a collector plate. Usually, the positive potential of the voltage source is connected to the needle, and the collector is grounded. The positive charges in the polymeric solution distort the droplet at the end of the capillary creating the so-called Taylor cone [28] that produces a polymer solution jet traveling from the capillary to the collector. In the process, the solvent evaporates, and the solid fibers deposit onto the collector [29-33].

The aim of this work was to prepare solid dispersion of LAP and PVP with electrospinning technique to increase the solubility and dissolution of LAP for future formulations that can be efficient in breast cancer therapy. Furthermore, we wished to determine the optimal electrospinning conditions that result in a bead-free fiber mat solid dispersion, then to examine the microstructure of the produced fiber mats and benchmark the dissolution of LAP from the solid dispersion to the pure crystalline LAP.

\section{Experimental}

\subsection{Materials}

Lapatinib as a ditosylate monohydrate salt was obtained as a gift sample from a local pharmaceutical company in Targu Mures, Romania. Ethanol (EtOH, Merck, ACS grade), dimethylformamide (DMF, Sigma Aldrich, ACS grade), dimethyl sulfoxide (DMSO, Merck, ACS grade), polyvinyl pyrrolidone (PVP K90, Sigma Aldrich, 1-1.7 M g/mol), toluene (GC quality, Merck, Germany) were obtained through local vendors and used without further purification. Hydrochloric acid (32\%) was from Riedel-de-Haen, while sodium dihydrogen phosphate and sodium hydroxide granules were obtained from Merck (ACS grade). Distilled water was used for the preparation of all aqueous solutions, apart from those for chromatographic purposes. For the latter, ultrapure, deionized water was used, as prepared by a Barnsted Nanopure Diamond Barnstead International Company, Iowa, USA water purification system.

\subsection{Polymeric solution preparation}

The polymer solution was prepared by the dissolution of $100 \mathrm{mg}$ of LAP-DT in $1.5 \mathrm{ml}$ of DMF and
$1.5 \mathrm{ml}$ of EtOH that resulted in a clear yellow solution. Afterwards, $480 \mathrm{mg}$ PVP was added, resulting in $15 \mathrm{w} / \mathrm{w} \% \mathrm{PVP}$ and $3.1 \mathrm{w} / \mathrm{w} \%$ LAP-DT concentration. The mixture was stirred by a magnetic stirrer, JK SMS HS (JKI, Shanghai, China), at $20^{\circ} \mathrm{C}$ for 15 minutes at $500 \mathrm{rpm}$ (rotation per minute) to obtain a clear, homogeneous, yellow, viscous polymeric solution.

\subsection{Fiber production by electrospinning}

Fiber mat production was carried out on a custombuilt single capillary electrospinning setup [34]. The syringe, containing the polymeric solution, was connected by a $3.2 \mathrm{~mm}$ inner diameter PTFE tubing to a needle and placed into a syringe pump (Ascor AP 12, Ascor Med, Warsaw, Poland). The $0.8 \mathrm{~mm}$ inner diameter needle was connected to the positive potential outlet of a high voltage DC power supply (ES50, Gamma High Voltage Research, USA) while the collector was grounded. A custom-built rotating drum collector ( $115 \mathrm{~mm}$ in diameter) was employed for fiber collection at $300 \mathrm{rpm}$. The needle was positioned at the center of the drum during the electrospinning process. The electrospinning process was carried out at $20{ }^{\circ} \mathrm{C}$ and $30 \%$ relative humidity, while the applied voltage $(V)$ was set to $14 \mathrm{kV}$, the needle-to-collector distance $(D)$ to $10 \mathrm{~cm}$, and the flow rate of the polymer solution was $0.9 \mathrm{ml} / \mathrm{h}$.

\subsection{Scanning electron microscopy (SEM)}

SEM images were taken by a JEOL 6380LA (Japan) type scanning electron microscope at $15 \mathrm{kV}$ on $\mathrm{Au}$ sputter-coated samples. The average fiber diameter was determined based on the diameter of 200 randomly selected fibers, measured in 5 SEM images taken at different parts of the sample. ImageJ software was used to measure the fiber diameters on the SEM images.

\subsection{Differential scanning calorimetry (DSC)}

DSC measurements were performed on a DSC Q2000 (TA Instruments, USA) instrument in a heat/cool/heat cycle in the temperature range of 30 to $300^{\circ} \mathrm{C}$ at $10^{\circ} \mathrm{C} / \mathrm{min}$ heating/cooling rate. Samples $(5-10 \mathrm{mg}$ ) were weighed and placed into aluminum pans. The measurements were carried out in nitrogen atmosphere (purge flow: $50 \mathrm{ml} / \mathrm{min}$ ), while an empty aluminum sample holder of the same type was used as reference. 


\subsection{Raman spectroscopy}

Raman spectroscopy was carried out on a Horiba Jobin Yvon (France) Labram type instrument with an external laser operating at $785 \mathrm{~nm}$ wavelength at $80 \mathrm{~mW}$ power coupled with an Olympus BX-40 type optical microscope. The spectra were collected between $1650-430 \mathrm{~cm}^{-1}$ wavenumbers.

\subsection{Gas chromatographic (GC) analysis of residual solvents}

Determination of residual solvent was performed on a Shimadzu GC-8A gas chromatograph with FID detector (Shimadzu, Japan). A Porapak-N 80/100 GC column was used with the following dimensions: $7.0 \mathrm{Ft}(1.2 \mathrm{~m}) \times 1 / 8$ in. $\times 2.1 \mathrm{~mm}(L \times O . D . \times I . D$.$) .$ Argon (Grade 4.7, Romsif Impex SRL, Romania) was used as the carrier gas; the pressure on the column was $2 \mathrm{~kg} / \mathrm{cm}^{2}$. Other method parameters were as follows:

- column oven temperature: $230^{\circ} \mathrm{C}$, isothermal;

- FID detector settings: $230^{\circ} \mathrm{C}$, hydrogen (Grade 4.5, Linde Romania; $\left.1 \mathrm{~kg} / \mathrm{cm}^{2}\right)$, air $\left(1 \mathrm{~kg} / \mathrm{cm}^{2}\right)$; range: 1 , attenuation: 2 ;

- injector temperature: $220^{\circ} \mathrm{C}$;

- manual injection $(0.4 \mu 1)$, using a Hamilton GC precision glass syringe.

Samples and standards were prepared in toluene. Approximately $32 \mathrm{mg}$ LAP-PVP nanofiber sample was weighted and cut into a $5 \times 5 \mathrm{~mm}^{2}$ pieces, sonicated in $2 \mathrm{ml}$ toluene for $60 \mathrm{mins}$, then centrifuged for $5 \mathrm{mins}$ at $4000 \mathrm{rpm}$. A volume of $0,4 \mu 1$ was injected into the apparatus using a precision $\mathrm{GC}$ syringe. All samples were prepared in triplicate.

The linearity of the method ranged between 5$100 \mathrm{ppm}$ in the case of EtOH and 100-1000 ppm for DMF. The accuracy and precision of the method were tested at three concentration levels. The precision of the method expressed as RSD value was below 5.4\% and relative errors for accuracy were lower than $9 \%$ for both analytes. The retention times of EtOH and DMF were $1.15 \mathrm{~min}$ and $2.1 \mathrm{~min}$, respectively.

\subsection{Determination of drug content}

LAP content of the prepared nanofibrous mat was performed using high-performance liquid chromatography (HPLC). The analyses were performed on a Finnigan Surveyor system (Thermo Finnigan, San Jose, CA, USA), equipped with a quaternary pump, an autosampler with a column thermostat, and a dual-wavelength detector. Chromquest 4.0 was used for data acquisition and analysis. The chromatographic column employed was a Hypersil BDS C18 $100 \times 4.6 \mathrm{~mm}, 3 \mu \mathrm{m}$ average particle size (Thermo Fischer Scientific, Waltham, USA). The mobile phase consisted of $50 \mathrm{mM}$ phosphate buffer solution pH 3.0 and acetonitrile 60:40 (v/v\%). Separations were performed at a column temperature of $45^{\circ} \mathrm{C}$, using a $1.5 \mathrm{ml} / \mathrm{min}$ flow rate. Detection was performed at $309 \mathrm{~nm}$. Three separate samples were prepared, as follows: $\sim 58 \mathrm{mg}$ nanofibrous mat was weighted, cut into smaller pieces, and dissolved in a $10 \mathrm{ml}$ amber volumetric flask using DMF. After completion to sign with DMF, $1 \mathrm{ml}$ of the obtained solution was diluted to $10 \mathrm{ml}$ with phosphate buffer $\mathrm{pH}$ 3.0. The reference solution was prepared in the same manner after weighing $10 \mathrm{mg}$ of LAP. Duplicate injections were employed in all cases.

\subsection{Solubility determination}

Solubility of LAP-DT was determined in $\mathrm{HCl} 0.1 \mathrm{~N}$, water, and $0.2 \mathrm{M}$ phosphate buffer $\mathrm{pH} 6.8$, in duplicate. Briefly, $5 \mathrm{mg}$ of LAP was weighed in a glass vial and $5 \mathrm{~mL}$ media was added. The suspension was sonicated for 120 minutes in an ultrasonic bath, under constant cooling with ice, to maintain the temperature at approximately $20 \pm 2{ }^{\circ} \mathrm{C}$. After completion, the samples were filtered through $0.45 \mu \mathrm{m}$ PVDF filters (Chromafil Xtra PVDF-45-25, Macherey-Nagel, Düren, Germany), discarding the first $4 \mathrm{~mL}$ The abovementioned chromatographic conditions were used for the determination of the active, using the external standard method.

\subsection{In vitro dissolution studies}

Dissolution studies were performed in an in-house assembled small-volume dissolution setup, as described in our earlier work $[35,36]$. Dissolution volume was $20 \mathrm{ml}$, maintained at $37 \pm 1^{\circ} \mathrm{C}$, using an Erweka ET-1500I (Erweka, Hensenstamm, Germany) immersion thermostat. Two dissolution tests were performed, using $\mathrm{HCl} 0.1 \mathrm{~N}$ and $0.2 \mathrm{M}$ phosphate buffer $\mathrm{pH} 6.8$ as dissolution media. Samples of the active substance ( $\sim 10 \mathrm{mg}$ LAP) and nanofibrous mats, corresponding to the same concentration of the active $(\sim 58.5 \mathrm{mg})$, were placed in glass tubes and stirred with Teflon coated magnetic stir bars at $200 \mathrm{rpm}$ (JKI magnetic stirrer, JKI, Shanghai, China). At predetermined time points $(1,3,5,10,15$ and $30 \mathrm{mins}), 1-1 \mathrm{ml}$ of the sample was withdrawn and 
filtered through $0.45 \mu \mathrm{m}$ PVDF filters (Chromafil Xtra PVDF-45-25, Macherey-Nagel, Düren, Germany). The dissolution media was replaced with the same volume of preheated dissolution media. The abovementioned chromatographic parameters were used for the determination of the dissolved active, using the external standard method.

\section{Results and discussion}

\subsection{Fiber mat characterization}

In this study, we selected PVP due to our experience and previous results obtained as a polymeric carrier in producing nanofiber-based solid dispersions via electrospinning $[37,38]$. In order to increase the LAP content in the polymeric solutions yet still use a solvent that dissolves PVP, we selected DMF and DMSO for the first experiments. DMSO is a lower toxicity solvent, which is desirable in pharmaceutical applications. It was determined that $150 \mathrm{mg}$ of LAP-DT dissolves in $5 \mathrm{ml}$ of DMSO, resulting in a clear yellow solution. To produce LAP-loaded PVP fibers, a $13 \mathrm{w} / \mathrm{w} \%$ PVP solution was prepared containing $2.3 \mathrm{w} / \mathrm{w} \%$ LAP in DMSO. The electrospinning process resulted in the formation of a Taylor cone and a stable polymer jet at multiple conditions; however, no solid fibers were obtained, even at $50 \mathrm{kV}$ applied voltage, rather a wet layer formed on the collector. In order to increase the volatility of the solution, EtOH was used in model experiments up to a 1:1 ratio, however, the results were the same.

Next, we examined DMF as solvent. 13 w/w\% PVP solution was prepared with $2.6 \mathrm{w} / \mathrm{w} \% \mathrm{LAP}$ in DMF; however, we were unable to produce fibers; instead,

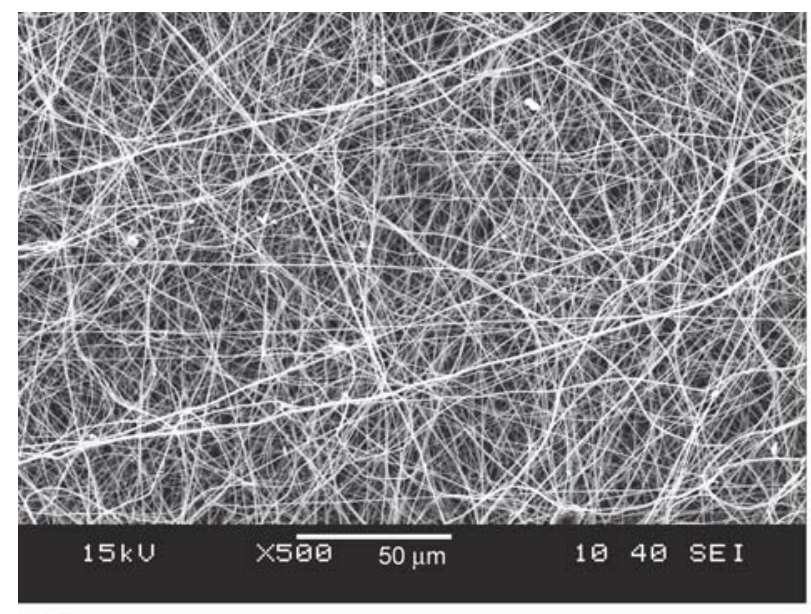

a) a thin film formed. Satisfactory results were obtained when EtOH was introduced in 1:1 (v:v) ratio to DMF. A systematic study of the electrospinning process parameters of voltage $(V)$, collector distance $(D)$ and flow rate $(F)$ suggested that stable fiber formation occurred at $D=10 \mathrm{~cm}$ and $V=13-14 \mathrm{kV}$ using a $15 \mathrm{w} / \mathrm{w} \%$ PVP and $3.1 \mathrm{w} / \mathrm{w} \%$ LAP solution in 1:1 (v:v) DMF:EtOH solvent system. The maximum flow rate, thus the production rate was determined to be $F=0.9 \mathrm{ml} / \mathrm{h}$. SEM images of the produced fiber mats can be seen in Figure 1. The abovementioned results indicate the need of fine-tuning the electrospinning conditions, both process and polymeric solution related, in order to produce LAPloaded PVP nanofibers with maximized LAP content. The resulting LAP-loaded PVP nanofibers were randomly oriented, smooth-surfaced, and bead-free with an average fiber diameter of $462 \pm 160 \mathrm{~nm}$. As the histogram in the inset of Figure $1 \mathrm{~b}$ shows, the individual fiber diameters range from $\sim 135$ to $\sim 1300 \mathrm{~nm}$; however, most of the fibers are in the $\sim 400 \mathrm{~nm}$ range.

\subsection{DSC results}

Figure 2 shows the thermograms of the neat polymer, PVP, the active pharmaceutical ingredient, LAP-DT, and the prepared LAP-loaded PVP nanofibers, respectively. The thermogram of PVP shows a broad endothermic peak between 50 to $125^{\circ} \mathrm{C}$, most probably due to the dehydration of the polymeric material. The broad endotherm peak did not appear on the second heating cycle of the heat-cool-heat DSC cycle. The $T_{\mathrm{g}}$ of amorphous PVP was measured to be $178.6{ }^{\circ} \mathrm{C}$, which shows good agreement with

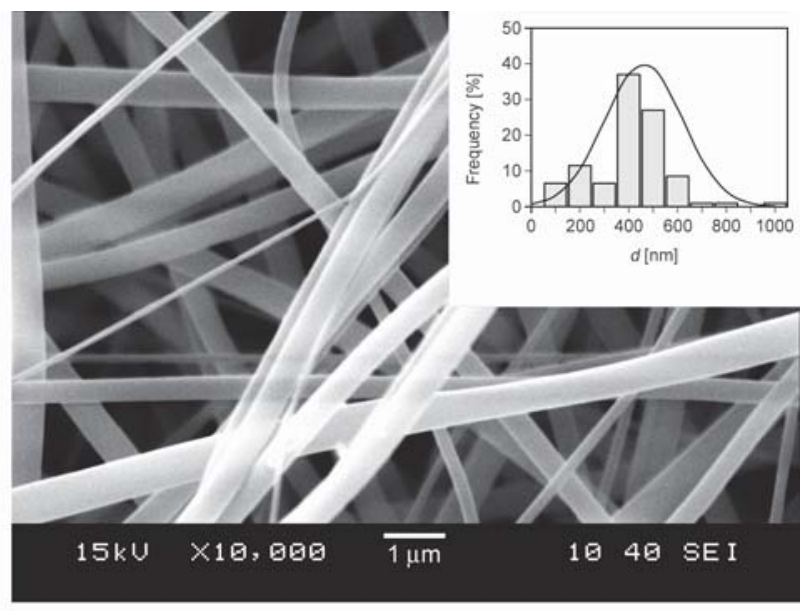

b)

Figure 1. SEM images of LAP-loaded PVP nanofiber mats at a) $500 \times$ magnification and at b) $10000 \times$ magnification with the fiber diameter histogram overlayed with the normal distribution from $15 \mathrm{w} / \mathrm{w} \% \mathrm{PVP}$ and $3.1 \mathrm{w} / \mathrm{w} \% \mathrm{LAP}$ solution in 1:1 DMF:EtOH at $F=0.9 \mathrm{ml} / \mathrm{h}, D=10 \mathrm{~cm}$ and $V=13.5 \mathrm{kV}$. 


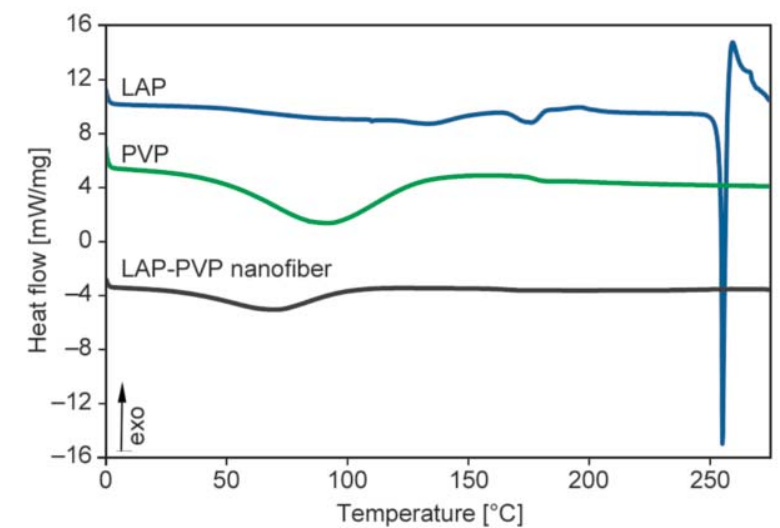

Figure 2. DSC thermograms of LAP-DT (blue), PVP (green) and LAP-loaded PVP nanofibers (black).

the literature [39]. The thermogram of LAP-DT shows three endotherm peaks with onsets at approximately 125,166 , and $251^{\circ} \mathrm{C}$ and the related peak maximums at approximately 133,175 , and $255^{\circ} \mathrm{C}$, respectively. Peaks at 125 and at $166^{\circ} \mathrm{C}$ are present on the thermogram due to the polymorphic structure of LAP, representing most probably Form II and Form I crystalline structure of LAP, respectively [40, 41]. The large and narrow endothermic peak at $255^{\circ} \mathrm{C}$ indicates the crystal melting and hence the crystalline nature of LAP-DT. The LAP-loaded PVP nanofiber thermogram shows a broad peak below $100^{\circ} \mathrm{C}$, most probably a dehydration peak, and a glass transition region, at $T_{\mathrm{g}}=\sim 167^{\circ} \mathrm{C}$. The lack of any endothermic peak at $255^{\circ} \mathrm{C}$ can be an indicator that the LAP-DT is in the amorphous state within the PVP nanofibers. The decrease in $T_{\mathrm{g}}$ of PVP is due to the mixing of the two amorphous materials as described in the literature [20].

\subsection{Raman spectroscopy results}

Raman spectroscopy was used to investigate the distribution of the API in the LAP-loaded PVP nanofibers. In order to determine the presence of LAP in the nanofibers, the Raman spectra of PVP, LAP, and LAP-loaded PVP nanofibers were collected and presented in Figure 3. The Raman spectra of LAP show six distinct peaks/ peak groups, and based on the literature, these could be assigned for the following functional groups: at approximately $800(\mathrm{C}-\mathrm{Cl}), 1210$ $(\mathrm{C}-\mathrm{O}-\mathrm{C}), 1300(\mathrm{O}=\mathrm{S}=\mathrm{O}), 1550$, and at $1609 \mathrm{~cm}^{-1}$ [42]. These significant peaks/ peak groups are marked with an asterisk "**" on the spectra. PVP also shows peaks at characteristic wavenumbers: $754(\mathrm{C}-\mathrm{C}$ ring), $851(\mathrm{C}-\mathrm{C}), 933$ (C-C ring breathing), 1023 (C-C backbone), 1344 and 1370 (C-H deformation),

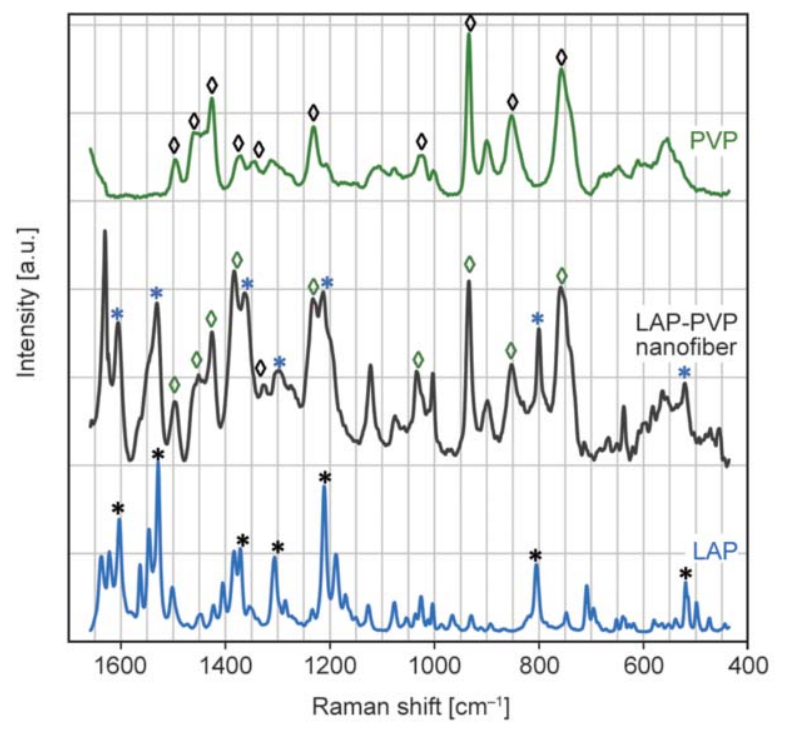

Figure 3. Raman spectra of PVP (green), LAP-loaded PVP nanofibers (black), and LAP (blue) over the wavenumber interval of $1650-430 \mathrm{~cm}^{-1}$.

1425-1456-1494 cm $\mathrm{cm}^{-1}\left(\mathrm{CH}_{2}\right.$ scissor) [43]. These peaks were marked with " $\diamond$ " in Figure 3. One can observe that the Raman spectra of LAP-loaded PVP nanofiber contain both sets of peaks, those that correspond to the PVP structure (marked with " $\diamond$ ") and those corresponding to the LAP structure (marked with "*"). It could also be observed that the peaks corresponding to LAP in the LAP-loaded PVP nanofiber spectra are a bit broader than in the neat drug. The peak broadening could be attributed to the amorphous state of the LAP in the PVP nanofiber [44, 45]. These findings are in good agreement with the DSC results. Measurements were performed on three different parts of the nanofiber sample, which showed the same Raman spectra, indicating the homogeneous distribution of LAP in the produced solid dispersion. Based on these results, we can conclude that we successfully made an amorphous solid dispersion of LAP in the PVP nanofiber matrix.

\subsection{GC results}

As the prepared nanofibrous mats were electrospun from organic solvents, it is essential to determine the residual solvent content of the obtained product. EtOH is a Class 3 solvent with low toxic potential, as described in ICH Guideline Q3C. These solvents are less toxic and present a lower risk to human health. Usually, a limit of $5000 \mathrm{ppm}$ is acceptable for Class 3 solvents in pharmaceutical products without justification. DMF, the solvent necessary for dissolving LAP, is classified as a Class 2 solvent, considered 
to be a solvent to be limited because of its inherent toxicity. The concentration limit for DMF is limited at $880 \mathrm{ppm}$.

The determined values of $10.9 \pm 2.3 \mathrm{ppm}$ for $\mathrm{EtOH}$ and $780 \pm 56 \mathrm{ppm}$ for DMF by GC are below the abovementioned limits, which means that most of these solvents evaporate properly during the electrospinning process. The presence of lower levels of $\mathrm{EtOH}$ in the fibers is most probably due to the lower boiling point $\left(78^{\circ} \mathrm{C}\right)$ of the solvent resulting in a higher evaporation rate during the electrospinning process, whereas the relatively high amount of DMF is most probably due to the high boiling point $\left(153^{\circ} \mathrm{C}\right)$ of the solvent, thus the lower evaporation rate during the electrospinning process. The solvent levels in the LAP-loaded PVP fibers could be further lowered using vacuum drying.

\subsection{Drug content of the prepared nanofibers}

In order to confirm the presence of LAP in the PVP nanofibers and to determine the drug loading of the prepared products, HPLC was used. Based on the HPLC results, the nanofibrous webs contain $16.76 \pm 0.11 \mathrm{w} / \mathrm{w} \%$ LAP $(n=3)$, which corresponds to $97.19 \pm 0.64 \%$ of the theoretical LAP content $(17.24 \mathrm{w} / \mathrm{w} \%)$. This finding, together with the DSC and Raman results, indicates that all of the used LAP to prepare the polymeric solution are present in the LAP-loaded PVP nanofibers.

\subsection{Solubility and in vitro dissolution studies}

Solubility of LAP-DT was determined in various media at $20 \pm 2{ }^{\circ} \mathrm{C}$. The results indicate that LAP is slightly soluble in $\mathrm{HCl} 0.1 \mathrm{~N}(297.1 \pm 28.4 \mu \mathrm{g} / \mathrm{ml})$; however, its solubility rapidly decreases in water
$(3.1 \pm 0.1 \mu \mathrm{g} / \mathrm{ml})$, and it is practically insoluble in $0.2 \mathrm{M}$ phosphate buffer $\mathrm{pH} 6.8(<0.05 \mu \mathrm{g} / \mathrm{ml})$.

Figure 4 depicts the comparative dissolution curves for the LAP-loaded PVP nanofibers and the LAP in $0.1 \mathrm{~N} \mathrm{HCl}$ (Figure $4 \mathrm{a}$ ) and $0.2 \mathrm{M}$ phosphate buffer pH 6.8 (Figure 4b) as dissolution media.

Neat LAP dissolved at low pH (approx. 80\%, after $30 \mathrm{~min}$ ) shown in Figure 4a that correlates well with the literature [21], due to the presence of the dicationic form. At pH 6.8, where the monocationic and neutral forms predominate, the dissolved concentrations were lower than the LOQ of the employed chromatographic method, Figure $4 \mathrm{~b}$. This result correlates well with literature [20] data showing only $~ 5 \%$ LAP dissolved in $0.2 \%(\mathrm{w} / \mathrm{v})$ SDS in water dissolution media where SDS was used to enhance the dissolution of LAP. In contrast, the disintegration of the prepared nanofibrous material was instantaneous, most probably due to the increased surface area when it comes in contact with the dissolution media. As it can be observed from the obtained data, the prepared LAP-loaded PVP nanofibrous mat solid dispersion presents $\sim 100 \%$ LAP dissolution in the $0.1 \mathrm{~N} \mathrm{HCl}$ whereas an over $\sim 60 \%$ dissolution even at $\mathrm{pH} 6.8$. This could most likely be explained by the crystalline to amorphous transition of the API by the electrospinning process. The LAP dissolution results from the LAP-loaded PVP nanofiber mats correlate well with the literature [20,21], thus indicating that electrospinning is a viable process to prepare LAPloaded solid dispersions.

\section{Conclusions}

In conclusion, solid dispersion of LAP and PVP were prepared by electrospinning for the first time.

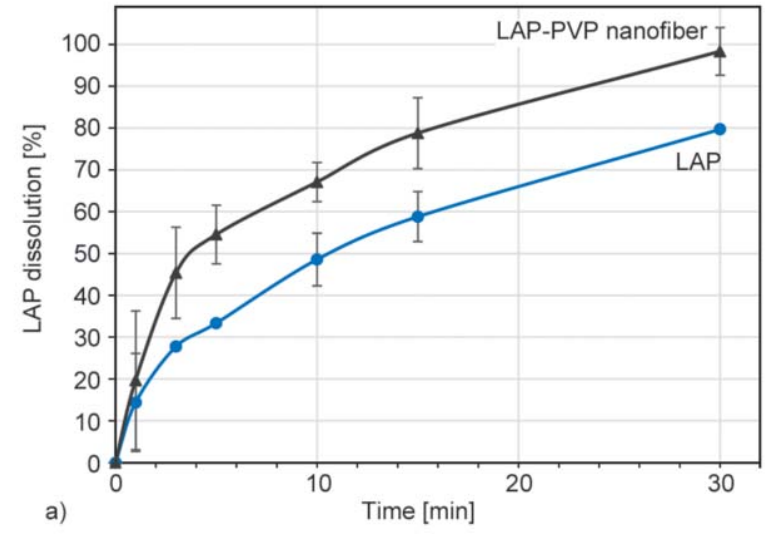

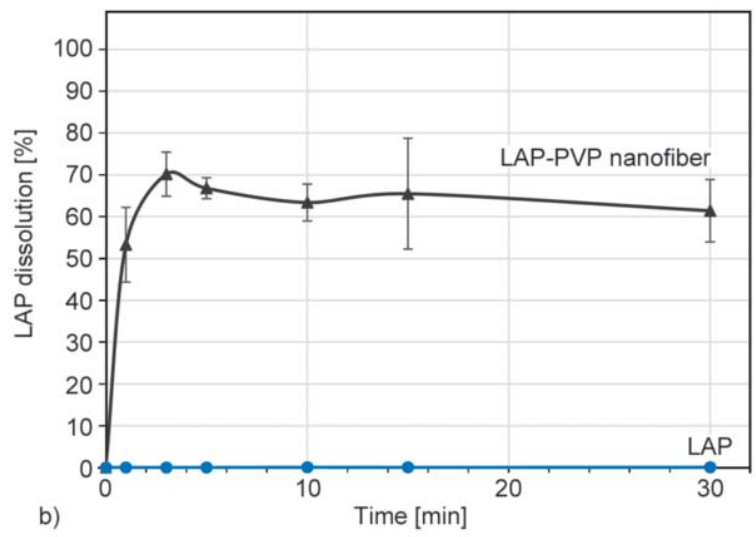

Figure 4. Dissolution curves of LAP-loaded PVP nanofiber and neat LAP in a) $0.1 \mathrm{~N} \mathrm{HCl}$ dissolution media and b) $0.2 \mathrm{M}$ and $0.2 \mathrm{M}$ phosphate buffer $\mathrm{pH} 6.8$. 
Using DMSO or DMF alone as solvent did not result in fiber formation; however, the use of 1:1 ratio of DMF:EtOH solvent system resulted in a stable electrospinning process. The produced fibers were smooth surfaced, bead-free, and planarly randomly oriented with an average fiber diameter of $462 \pm 160 \mathrm{~nm}$. DSC results suggest that LAP is in the amorphous state within the PVP fiber, whereas Raman spectroscopy confirms this and indicates a homogeneous distribution of the cancer drug in the nanofiber mat solid dispersion. The dissolution studies further underline these findings, presenting an increase in solubility and dissolution of the active ingredient, especially in $\mathrm{pH} 6.8$, where over $60 \%$ is dissolved from the nanofibrous samples, compared to approximately $0.1 \%$ from the neat active ingredient. It was confirmed by the $\mathrm{GC}$ results that the residual solvent in the LAP-loaded PVP fibers was below the recommended levels. The obtained results could be a new starting point for the development of novel LAP formulations with increased solubility and bioavailability for breast cancer treatment.

\section{Acknowledgements}

The authors wish to thank the support for this project to the Domus Grant of the Hungarian Academy of Sciences. Kolos Molnár would like to thank the János Bolyai Scholarship of the Hungarian Academy of Sciences and the ÚNKP-20-5 New National Excellence Program of the Ministry for Innovation and Technology for their kind support.

\section{References}

[1] Sung H., Ferlay J., Siegel R. L., Laversanne M., Soerjomataram I., Jemal A., Bray F.: Global cancer statistics 2020: GLOBOCAN estimates of incidence and mortality worldwide for 36 cancers in 185 countries. CA: A Cancer Journal for Clinicians, 71, 209-249 (2021). https://doi.org/10.3322/caac. 21660

[2] Anirudhan T. S., Sekhar V. C.: Fabrication of functionalized layered double hydroxide/chitosan nanocomposite with dual responsive drug release for the targeted therapy of breast cancer. European Polymer Journal, 139, 109993/1-109993/11 (2020). https://doi.org/10.1016/j.eurpolymj.2020.109993

[3] Slamon D. J., Godolphin W., Jones L. A., Holt J. A., Wong S. G., Keith D. E., Levin W. J., Stuart S. G., Udove J., Ullrich A.: Studies of the HER-2/neu protooncogene in human breast and ovarian cancer. Science, 244, 707-712 (1989). https://doi.org/10.1126/science.2470152
[4] Ma F., Ouyang Q., Li W., Jiang Z., Tong Z., Liu Y., Li H., Yu S., Feng J., Wang S., Hu M., Zhou J., Xu B.: Pyrotinib or lapatinib combined with capecitabine in HER2-Positive metastatic breast cancer with prior taxanes, anthracyclines, and/or trastuzumab: A randomized, phase II study. Journal of Clinical Oncology, 37, 2610-2619 (2019).

https://doi.org/10.1200/JCO.19.00108

[5] Supasena W., Muangnoi C., Praengam K., Wong T. W., Qiu G., Ye S., Wu J., Tanasupawat S., Rojsitthisak P.: Enhanced selective cytotoxicity of doxorubicin to breast cancer cells by methoxypolyethylene glycol conjugation via a novel beta-thiopropanamide linker. European Polymer Journal, 141, 110056/1-110056/10 (2020). https://doi.org/10.1016/j.eurpolymj.2020.110056

[6] Sedghi R., Gholami M., Shaabani A., Saber M., Niknejad H.: Preparation of novel chitosan derivative nanofibers for prevention of breast cancer recurrence. European Polymer Journal, 123, 109421/1-109421/9 (2020).

https://doi.org/10.1016/j.eurpolymj.2019.109421

[7] Oh D-Y., Bang Y-J.: HER2-targeted therapies - A role beyond breast cancer. Nature Reviews Clinical Oncology, 17, 33-48 (2020).

https://doi.org/10.1038/s41571-019-0268-3

[8] Goutsouliak K., Veeraraghavan J., Sethunath V., De Angelis C., Osborne C. K., Rimawi M. F., Schiff R.: Towards personalized treatment for early stage HER2positive breast cancer. Nature Reviews Clinical Oncology, 17, 233-250 (2020).

https://doi.org/10.1038/s41571-019-0299-9

[9] Higa G. M., Abraham J.: Lapatinib in the treatment of breast cancer. Expert Review of Anticancer Therapy, 7, 1183-1192 (2007).

https://doi.org/10.1586/14737140.7.9.1183

[10] Ryan Q., Ibrahim A., Cohen M. H., Johnson J., Ko C-W., Sridhara R., Justice R., Pazdur R.: FDA drug approval summary: Lapatinib in combination with capecitabine for previously treated metastatic breast cancer that overexpresses HER-2. The Oncologist, 13, 1114-1119 (2008). https://doi.org/10.1634/theoncologist.2008-0816

[11] Fink C., Sun D., Wagner K., Schneider M., Bauer H., Dolgos H., Mäder K., Peters S-A.: Evaluating the role of solubility in oral absorption of poorly water-soluble drugs using physiologically-based pharmacokinetic modeling. Clinical Pharmacology and Therapeutics, 107, 650-661 (2020).

https://doi.org/10.1002/cpt.1672

[12] Burris H. A., Taylor C. W., Jones S. F., Koch K. M., Versola M. J., Arya N., Fleming R. A., Smith D. A., Pandite L., Spector N., Wilding G.: A phase I and pharmacokinetic study of oral lapatinib administered once or twice daily in patients with solid malignancies. Clinical Cancer Research, 15, 6702-6708 (2009). https://doi.org/10.1158/1078-0432.CCR-09-0369 
[13] Budha N. R., Frymoyer A., Smelick G. S., Jin J. Y., Yago M. R., Dresser M. J., Holden S. N., Benet L. Z., Ware J. A.: Drug absorption interactions between oral targeted anticancer agents and PPIs: Is $\mathrm{pH}$-dependent solubility the Achilles heel of targeted therapy? Clinical Pharmacology and Therapeutics, 92, 203-213 (2012). https://doi.org/10.1038/clpt.2012.73

[14] Devriese L. A., Koch K. M., Mergui-Roelvink M., Matthys G. M., Ma W. W., Robidoux A., Stephenson J. J., Chu Q. S. C., Orford K. W., Cartee L., Botbyl J., Ayra N., Schellend J. H. N.: Effects of low-fat and highfat meals on steady-state pharmacokinetics of lapatinib in patients with advanced solid tumours. Investigational New Drugs, 32, 481-488 (2014). https://doi.org/10.1007/s10637-013-0055-4

[15] Koch K. M., Im Y-H., Kim S-B., Ribate A. U., Stephenson J., Botbyl J., Cartee L., Holshouser J., Ridgway D.: Effects of esomeprazole on the pharmacokinetics of lapatinib in breast cancer patients. Clinical Pharmacology in Drug Development, 2, 336-341 (2013). https://doi.org/10.1002/cpdd.45

[16] Leuner C., Dressman J.: Improving drug solubility for oral delivery using solid dispersions. European Journal of Pharmaceutics and Biopharmaceutics, 50, 47-60 (2000). https://doi.org/10.1016/S0939-6411(00)00076-X

[17] Williams H. D., Trevaskis N. L., Charman S. A., Shanker R. M., Charman W. N., Pouton C. W., Porter C. J. H., Christopoulos A.: Strategies to address low drug solubility in discovery and development. Pharmacological Reviews, 65, 315-499 (2013). https://doi.org/10.1124/pr.112.005660

[18] Koprivova B., Lisnenko M., Solarska-Sciuk K., Prochazkova R., Novotny V., Mullerova J., Mikes P., Jencova V.: Large-scale electrospinning of poly (vinylalcohol) nanofibers incorporated with platelet-derived growth factors. Express Polymer Letters, 14, 987-1000 (2020). https://doi.org/10.3144/expresspolymlett.2020.80

[19] Nagy N. Z., Varga Z., Mihály J., Kasza G., Iván B., Kiss É.: Highly efficient encapsulation of curcumin into and $\mathrm{pH}$-controlled drug release from poly( $\varepsilon$-caprolactone) nanoparticles stabilized with a novel amphiphilic hyperbranched polyglycerol. Express Polymer Letters, 14, 90-101 (2020).

https://doi.org/10.3144/expresspolymlett.2020.8

[20] Song Y., Yang X., Chen X., Nie H., Byrn S., Lubach J. W.: Investigation of drug-excipient interactions in lapatinib amorphous solid dispersions using solid-state NMR spectroscopy. Molecular Pharmaceutics, 12, 857 866 (2015).

https://doi.org/10.1021/mp500692a

[21] Hu X-Y., Lou H., Hageman M. J.: Preparation of lapatinib ditosylate solid dispersions using solvent rotary evaporation and hot melt extrusion for solubility and dissolution enhancement. International Journal of Pharmaceutics, 552, 154-163 (2018).

https://doi.org/10.1016/j.ijpharm.2018.09.062
[22] Mitrabhanu M., Apte S. S., Pavani A., Appadwedula V. S.: Solubility improvement of lapatinib by novel techniques of solid dispersion. Research Journal of Pharmacy and Technology, 12, 1664-1676 (2019). https://doi.org/10.5958/0974-360X.2019.00279.8

[23] Gao H., Wang Y., Chen C., Chen J., Wei Y., Cao S., Jiang $\mathrm{X}$.: Incorporation of lapatinib into core-shell nanoparticles improves both the solubility and anti-glioma effects of the drug. International Journal of Pharmaceutics, 461, 478-488 (2014).

https://doi.org/10.1016/j.ijpharm.2013.12.016

[24] Wang H., Li F., Du C., Wang H., Mahato R. I., Huang Y.: Doxorubicin and lapatinib combination nanomedicine for treating resistant breast cancer. Molecular Pharmaceutics, 11, 2600-2611 (2014). https://doi.org/10.1021/mp400687w

[25] Yu D-G., Li J-J., Williams G. R., Zhao M.: Electrospun amorphous solid dispersions of poorly water-soluble drugs: A review. Journal of Controlled Release, 292, 91-110 (2018).

https://doi.org/10.1016/j.jconrel.2018.08.016

[26] Nagy Zs. K., Balogh A., Démuth B., Pataki H., Vigh T., Szabó B., Molnár K., Schmidt B. T., Horák P., Marosi Gy., Verreck G., van Assche I., Brewster M. E.: High speed electrospinning for scaled-up production of amorphous solid dispersion of itraconazole. International Journal of Pharmaceutics, 480, 137-142 (2015). https://doi.org/10.1016/j.ijpharm.2015.01.025

[27] Démuth B., Farkas A., Pataki H., Balogh A., Szabó B., Borbás E., Sóti P. L., Vigh T., Kiserdei É., Farkas B., Mensch J., Verreck G., van Assche I., Marosi Gy., Nagy Zs. K.: Detailed stability investigation of amorphous solid dispersions prepared by single-needle and high speed electrospinning. International Journal of Pharmaceutics, 498, 234-244 (2016).

https://doi.org/10.1016/j.ijpharm.2015.12.029

[28] Taylor G. I.: Electrically driven jets. Proceedings of the Royal Society of London A: Mathematical Physical and Engineering Sciences, 313, 453-475 (1969). https://doi.org/10.1098/rspa.1969.0205

[29] Reneker D. H., Chun I.: Nanometre diameter fibres of polymer, produced by electrospinning. Nanotechnology, 7, 216-223 (1996). https://doi.org/10.1088/0957-4484/7/3/009

[30] Doshi J., Reneker D. H.: Electrospinning process and applications of electrospun fibers. Journal of Electrostatics, 35, 151-160 (1995). https://doi.org/10.1016/0304-3886(95)00041-8

[31] Bhardwaj N., Kundu S. C.: Electrospinning: A fascinating fiber fabrication technique. Biotechnology Advances, 28, 325-347 (2010). https://doi.org/10.1016/j.biotechadv.2010.01.004

[32] Khan W. S., Asmatulu R., Ceylan M., Jabbarnia A.: Recent progress on conventional and non-conventional electrospinning processes. Fibers and Polymers, 14, 1235-1247 (2013).

https://doi.org/10.1007/s12221-013-1235-8 
[33] Wu C. M., Chou M. H.: Acoustic-electric conversion and piezoelectric properties of electrospun polyvinylidene fluoride/silver nanofibrous membranes. Express Polymer Letters, 14, 103-114 (2020).

https://doi.org/10.3144/expresspolymlett.2020.10

[34] Gergely A., Kántor J., Bitay E., Biró D.: Electrospinning of polymer fibres using recycled PET. Acta Materialia Transylvanica, 2, 19-26 (2019). https://doi.org/10.33924/amt-2019-01-04

[35] Sipos E., Szabó Z. I., Rédai E., Szabó P., Sebe I., Zelkó R.: Preparation and characterization of nanofibrous sheets for enhanced oral dissolution of nebivolol hydrochloride. Journal of Pharmaceutical and Biomedical Analysis, 129, 224-228 (2016). https://doi.org/10.1016/j.jpba.2016.07.004

[36] Sipos E., Kósa N., Kazsoki A., Szabó Z. I., Zelkó R.: Formulation and characterization of aceclofenac-loaded nanofiber based orally dissolving webs. Pharmaceutics, 11, 417-428 (2019). https://doi.org/10.3390/pharmaceutics11080417

[37] Sipos E., Csatári T., Kazsoki A., Gergely A., Bitay E., Szabó Z-I., Zelkó R.: Preparation and characterization of fenofibrate-loaded PVP electrospun microfibrous sheets. Pharmaceutics, 12, 612-622 (2020). https://doi.org/10.3390/pharmaceutics12070612

[38] Bitay E., Szabó Z-I., Kántor J., Molnar K., Gergely A. L.: Scale-up and optimization of fenofibrate-loaded fibers electrospun by corona-electrospinning. Express Polymer Letters, 15, 375-387 (2021). https://doi.org/10.3144/expresspolymlett.2021.32
[39] Asgreen C., Knopp M. M., Skytte J., Löbmann K.: Influence of the polymer glass transition temperature and molecular weight on drug amorphization kinetics using ball milling. Pharmaceutics, 12, 483/1-483/6 (2020). https://doi.org/10.3390/pharmaceutics12060483

[40] de Araujo G. L. B., Zeller M., Smith D., Nie H., Byrn S. R.: Unexpected single crystal growth induced by a wire and new crystalline structures of lapatinib. Crystal Growth and Design, 16, 6122-6130 (2016). https://doi.org/10.1021/acs.cgd.6b01271

[41] Zetina-Rocha C., Cammisa E. G., Weeratunga G.: Polymorphic forms of lapatinib ditosylate and processes for their preparation. U.S. Patent 8993579B2, USA (2011).

[42] Wan X., Zheng X., Pang X., Zhang Z., Zhang Q.: Incorporation of lapatinib into human serum albumin nanoparticles with enhanced anti-tumor effects in HER2positive breast cancer. Colloids and Surfaces B: Biointerfaces, 136, 817-827 (2015).

https://doi.org/10.1016/j.colsurfb.2015.10.018

[43] Taylor L. S., Langkilde F. W., Zografi G.: Fourier transform Raman spectroscopic study of the interaction of water vapor with amorphous polymers. Journal of Pharmaceutical Sciences, 90, 888-901 (2001). https://doi.org/10.1002/jps.1041

[44] Andrikopoulos K. S., Yannopoulos S. N., Voyiatzis G. A., Kolobov A. V., Ribes M., Tominaga J.: Raman scattering study of the a-GeTe structure and possible mechanism for the amorphous to crystal transition. Journal of Physics: Condensed Matter, 18, 965-979 (2006). https://doi.org/10.1088/0953-8984/18/3/014

[45] Tuschel D.: Why are the Raman spectra of crystalline and amorphous solids different. Spectroscopy, 32, 2633 (2017). 